\title{
Clinical Study \\ Clinical Spectrum of Propionic Acidaemia
}

\author{
Muhammad Rafique \\ Department of Child Health, College of Medicine, King Khalid University, Abha 61321, Saudi Arabia
}

Correspondence should be addressed to Muhammad Rafique; mrafiquelhr@hotmail.com

Received 21 March 2013; Accepted 12 September 2013

Academic Editor: H. K. Biesalski

Copyright (C) 2013 Muhammad Rafique. This is an open access article distributed under the Creative Commons Attribution License, which permits unrestricted use, distribution, and reproduction in any medium, provided the original work is properly cited.

Objectives. To evaluate the clinical features, physical findings, diagnosis, and laboratory parameters of the patients with propionic acidaemia (PA). Methods. The records of diagnosed cases of propionic acidaemia were reviewed, retrospectively. Results. Twentysix patients with PA had 133 admissions. The majority (85\%) of the patients exhibited clinical manifestations in the 1st week of life. Regarding clinical features, lethargy, fever, poor feeding, vomiting, dehydration, muscular hypotonia, respiratory symptoms, encephalopathy, disturbance of tone and reflexes, and malnutrition were observed in 51-92\% admissions. Metabolic crises, respiratory diseases, hyperammonaemia, metabolic acidosis, hypoalbuminaemia, and hypocalcaemia were observed in 30-96\% admissions. Pancytopenia, ketonuria, hypoproteinemia, hypoglycaemia, and mildly disturbed liver enzymes were found in $12-41 \%$ admissions. Generalised brain oedema was detected in $17 \%$ and cerebral atrophy in $25 \%$ admissions. Gender-wise odd ratio analysis showed value of 1.9 for lethargy, 1.99 for respiratory diseases, 0.55 for anaemia, and 1.82 for hypocalcaemia. Conclusion. Propionic acidaemia usually presents with wide spectrum of clinical features and disturbances of laboratory parameters in early neonatal age. It is associated with significant complications which deteriorate the patients' quality of life. Perhaps with early diagnosis of the disease and in time intervention, these may be preventable.

\section{Introduction}

Propionic acidaemia (PA) is a rare autosomal recessive metabolic disease. About $80 \%$ are early onset cases (who are diagnosed within three months of age) which classically present in the neonatal period with lethargy, vomiting, refusal to feed, hypotonia, and less frequently with dehydration and seizures $[1,2]$. Some patients show milder symptoms and long survival rate, associated with chronic late onset form [3]. In the individuals with $\mathrm{PA}$, serious health problems can be triggered by prolonged fasting, fever or infections, and high protein diet leading to accumulation of toxic substances [2].

Hyperammonaemia is the most common presentation found in $88 \%$, patients [2]. The disease is also characterized by repeated episodes of metabolic acidosis, occasionally seizures, coma, and cerebellar haemorrhages [4]. Hypoglycaemia is a commonly described finding during metabolic decompensations but rarely hyperglycaemia and decreased bone density have also been reported [5]. Commonly observed viral infection and bone marrow suppression with neutropenia and thrombocytopenia in patients with PA might be lethal $[3,6]$.
There are few reports [8] of presentation of patients with PA from Kingdom of Saudi Arabia (KSA), yet none is available from south-west region of KSA. So, this study was carried out to find out the clinical features, physical findings, laboratory parameters, and diagnosis of the diseases with which the patients with PA were admitted to the hospital.

\section{Methods}

The study was conducted in a tertiary care, referral, public hospital, during the period of January 2001-December 2012, retrospectively. The records were ascertained of all admitted Saudi patients in the department of Paediatrics with confirmed diagnosis of PA (on basis of high propionylcarnitine level in blood, detected by tandem mass spectrometry, high level of propionate in urine, enzyme analysis, and genetic studies). All cases were reviewed for the variables of: age of the patients at diagnosis and present age, family history, clinical features, and detail of admissions. Weight and height/ length of the patients were noted and their percentages of normal for age of Saudi children were calculated. Under nutrition/wasting (weight $<$ normal for age) percentage was 
TABLE 1: Data of 26 patients with PA.

\begin{tabular}{lclc}
\hline Variable of patients & $n(\%) /$ mean $(\mathrm{SD})$ & Variables of patients & $n(\%) / \mathrm{mean}(\mathrm{SD})$ \\
\hline Male & $16(61.5)$ & No. of admission/patient & $5.1[6.5]$ \\
Female & $10(38.5)$ & Frequency of admission/yr & $4.2[3]$ \\
Mean age in yr & $2.85[4.8]$ & Early onset cases & $5.5[6.7]$ \\
Consanguinity of parents & $24(92.3)$ & Late onset cases & 2 \\
H/O of PA in siblings & $10(38.5)$ & Cerebral palsy & $4(15.4)$ \\
H/O NICU admission & $17(63.4)$ & Seizures & $12(46.2)$ \\
No. of deceased patients & $2(7.7)$ & Hypotonia & $11(42.3)$ \\
Time of clinical onset/diagnosis & & Hyporeflexia & $4(15.4)$ \\
1st week of life (early onset) & $22(84.6)$ & Hypertonia & $4(15.4)$ \\
2nd week-3months (early onset) & $2(7.7)$ & Hyperreflexia & $9(34.6)$ \\
$>3$ months of age (late onset) & $2(7.7)$ & Patients were & On NG/G tube feeding \\
Diagnosis age (range: 2 day-lyr) & $0.13[0.3]$ & On home oxygen therapy & $2(15.4)$ \\
Mean \% of weight for age & $72.4[17.1]$ & Look after in social home & $2(7.7)$ \\
Mean \% of height/length for age & $90.7[8.8]$ & & \\
\hline
\end{tabular}

Values are given in $n$ (\%) or mean (SD); H/O: history of, NICU: neonatal intensive care unit, NG/G: nasogastric/gastrostomy tube.

calculated and categorised according to Gomez classification of malnutrition. Short stature/stunting (height $<$ normal for age) percentage was calculated and categorised according to Waterlow classification of malnutrition [10]. The records were also reviewed for biochemical analysis, other relevant investigations, and diagnosis of the presenting diseases with which those patients of PA were admitted. The data were analyzed by using SPSS version 17. One sample $t$-test (Table 2) was applied to find out the significance of important variables which produced significant impact on patients of PA. The study was approved by the Research Ethical Committee of King Khalid University, Abha, KSA (Record no. 2012-10-08).

\section{Results}

Our study group included 26 patients with 133 admissions. Their (mean \pm SD) age at last admission was observed to be $4.3 \pm 4.7$ years. Table 1 demonstrates demographic characteristics of patients with PA.

Regarding diagnosis of PA, tandem mass spectrometry results showed mean propionylcarnitine level of $18.8 \pm$ $2.7 \mathrm{umol} / \mathrm{L}$ (normal: $<4.33$ ) and mean $\mathrm{C} 3 / \mathrm{C} 2$ ratio was $1.9 \pm$ 0.2 (normal: <0.1). In early onset cases, mean age was $2.95 \pm$ $4.95 \mathrm{yr}$ (range: 3 days-14 yr) and mean age of surviving patients was $2.24 \mathrm{yr}$ (range: 3 days-12.5 yr). Frequency of admissions/year in those cases was $5.5 \pm 6.7$. Mean age of two late onset cases was $1.05 \mathrm{yr}$; their hospital admissions were comparatively infrequent (2/yr) and no long-term neurological complications were detected in those patients. Mean hospital stay of children per admission was $9.2 \pm 8$ days (range 125). Patients' mean \pm SD weight, expected for age, was $72.4 \pm$ $17.1 \%$ (range: $43-98$, normal: $>80)$. Six $(23.1 \%)$ patients were having 1st and 2nd degree while 8 (30.1\%) children had $3 \mathrm{rd}$ degree, under nutrition/wasting [10]. Mean height/length, expected for age, was $90.7 \pm 8.8 \%$ (range: $67-101$, normal: $>95)$. Seven $(26.9 \%)$ patients had 1st degree, 8 (30.1\%) had 2nd degree, and 2 (7.7\%) had 3rd degree stunting/short stature [10]. Ratio of the PA patient admissions to all patient admissions in the paediatrics department was 1:252. Summary of clinical symptoms, physical findings, and diagnoses of the presenting diseases in patients with PA is given in Table 2. Clinical features detected were loose motions in $9.8 \%$, constipation in $6.8 \%$, dehydration in $92.5 \%$, hypotension in $7.5 \%$, shock in $12 \%$, hypotonia in $46 \%$, hyporeflexia in $19.6 \%$, hypertonia in $9 \%$, and hyperreflexia in $48.9 \%$ admissions. Regarding diagnoses of PA patients, acute watery diarrhoea was found in $9 \%$ and respiratory diseases like pneumonia, chronic lung diseases, upper respiratory tract infection, and hyperactive airway disease were seen in 30.1\% admissions. Among laboratory parameters, serum blood urea nitrogen (BUN) was found to be $49.7 \pm 26.3$ (mean \pm SD), creatinine $0.66 \pm 0.5 \mathrm{mg} / \mathrm{dL}$, sodium $139 \pm 9 \mathrm{mEq} / \mathrm{L}$, and potassium $4.1 \pm 0.6 \mathrm{mEq} / \mathrm{L}$. Among liver enzymes, AST was found to be

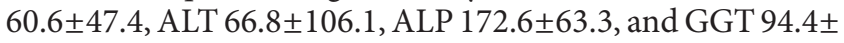
92.1 IU/L. Mean erythrocyte sedimentation rate was found to be $14.3 \pm 9.8 \mathrm{~mm}$ after the 1st hour. Among disturbances in laboratory values, we found hyperammonaemia (>80 mg/dL) in $96 \%$ and severe hyperammonaemia ( $>1000 \mathrm{mg} / \mathrm{dL}$ ) in $4.5 \%$ admissions. Hyperuraemia (BUN > $20 \mathrm{mg} / \mathrm{dL}$ ) was found in $91.7 \%$, hypercreatinemia ( $>1 \mathrm{mg} / \mathrm{dL})$ in $11.3 \%$, hypoalbuminaemia $(<3.5 \mathrm{~g} / \mathrm{dL})$ in $76.7 \%$, hyponatraemia $(<135 \mathrm{mEq} / \mathrm{L})$ in $23.3 \%$, and hypoklamia $(<3.5 \mathrm{mEq} / \mathrm{L})$ in $7.5 \%$ admissions. Raised liver enzymes were observed in 16.6-39.9\% admissions. In haematological parameters, neutropenia (absolute neutrophil count $(\mathrm{ANC})<1500 / \mathrm{mm}^{3}$ ) was found in $36.1 \%$ admissions, and of them, mean ANC was observed to be $892 / \mathrm{mm}^{3}$. Severe neutropenia (ANC $<500 / \mathrm{mm}^{3}$ ) was encountered in 5.3\% admissions. Erythrocytopenia (RBCs < $3.4 \times 10^{6} / \mathrm{mm}^{3}$ ) was also detected in $17.3 \%$ admissions. In arterial blood gases values, base excess $>-4$ was found in $94 \%$, acidosis $\left(\mathrm{HCO}_{3}<18 \mathrm{mmol} / \mathrm{L}\right)$ in $77 \%$, and alkalosis $\left(\mathrm{HCO}_{3}>\right.$ $28 / \mathrm{mm}^{3}$ ) in $8 \%$ admissions. Ketonuria was found in $35 \%$ admissions. Table 3 summarizes clinical features and laboratory data in patients with PA and comparison of those with other studies. Table 4 summarizes gender-wise odd ratio analysis of clinical features and laboratory findings. We 
TABLE 2: Important clinical, physical, and laboratory findings and diagnoses of diseases on initial presentation in 133 admissions of 26 patients with PA and comparison of these findings with other studies.

\begin{tabular}{|c|c|c|c|c|}
\hline Variables & Current study in \% & Lehnert et al. 1994 [2] & Other studies & $P$ value \\
\hline \multicolumn{5}{|l|}{ Symptoms } \\
\hline Lethargy/apathy/somnolence & 68 & 73 & $55^{\ddagger}$ & $<0.001$ \\
\hline Poor feeding and vomiting & 77 & 83 & $91^{\ddagger}$ & $<0.001$ \\
\hline Dyspnoea, cough, and others ${ }^{\dagger}$ & 36 & 57 & - & $<0.001$ \\
\hline Seizures & 13 & 43 & $23^{9}$ & $<0.001$ \\
\hline Loss of consciousness & 18 & - & $15^{9}$ & 0.013 \\
\hline \multicolumn{5}{|l|}{ Physical findings } \\
\hline Muscular hypotonia & 62 & 73 & $48^{9}$ & $<0.001$ \\
\hline Malnutrition & 80 & 59 & - & $<0.001$ \\
\hline \multicolumn{5}{|l|}{ Laboratory Parameters } \\
\hline Hyperammonaemia (>80 umol/L) & 96 & 88 & $100^{\ddagger}$ & 0.003 \\
\hline Hypoglycaemia $(<50 \mathrm{mg} / \mathrm{dL})$ & 12 & 17 & - & $<0.001$ \\
\hline Hyperglycaemia (>200 mg/dL) & 2 & 17 & - & $<0.001$ \\
\hline Hypoproteinemia $(<5.5 \mathrm{~g} / \mathrm{dL})$ & 27 & 33 & - & 0.013 \\
\hline Hypocalcaemia (<8.4 mg/dL) & 65 & - & $36^{\ddagger}$ & $<0.001$ \\
\hline Pancytopenia & 36 & 41 & - & 0.013 \\
\hline Anaemia $(\mathrm{Hb} .<10 \mathrm{~g} / \mathrm{dL})$ & 26 & 72 & - & $<0.001$ \\
\hline Thrombocytopenia $\left(<150,000 / \mathrm{mm}^{3}\right)$ & 39 & 62 & $18^{\ddagger}$ & $<0.001$ \\
\hline Neutropenia, ANC $\left(<1500 \times 10^{9} / \mathrm{L}\right)$ & 36 & 83 & $27^{\ddagger}$ & 0.002 \\
\hline Acidosis $\mathrm{pH}<7.35 / \mathrm{HCO}_{3}<18 \mathrm{mmol} / \mathrm{L}$ & 77 & 90 & $56^{\S}$ & 0.245 \\
\hline Alkalosis, $\mathrm{pH}>7.45 / \mathrm{HCO}_{3}>28 \mathrm{mmol} / \mathrm{L}$ & 8 & - & $18^{\ddagger}$ & $<0.001$ \\
\hline \multicolumn{5}{|l|}{ Diagnosis } \\
\hline Sepsis (culture proven) & 6 & - & $18^{\ddagger}$ & $<0.001$ \\
\hline Suspected sepsis & 33 & 60 & $85^{*}$ & $<0.001$ \\
\hline Death & 8 & 40 & $32^{\S}$ & $<0.001$ \\
\hline
\end{tabular}

Others $^{\dagger}$ : acidotic breathing aspiration, apnoea, suppurative otitis media, sore throat, flu; ${ }^{\ddagger}$ Walter et al., 1995 [7]; ${ }^{\$}$ Schreiber et al., 2012 [1]; ${ }^{\S}$ Ozand et al., 1994 [8]; ${ }^{*}$ Chapman et al., 2012 [9].

applied one sample $t$-test to important variables (Table 2). Our variables were compared with those of other studies. $P$ value $<0.05$ indicates significant difference in these variables.

\section{Discussion}

The incidence of PA is high in Saudi Arabia (1:2000-5000 live births) due to a relatively high rate of intrafamilial marriages. In this study, most (92\%) of the parents were consanguineous. However consanguinity was reported as $40 \%$ in another report from KSA [11]. The difference is probably due to cultural and social impact in the studied region.

4.1. Clinical Presentation. The majority (84\%) of the studied patients exhibited clinical manifestations in the 1st week and $92 \%$ in the first 2 weeks of life, while these figures were reported as $66 \%$ and $80 \%$, respectively, in an Austrian study [2]. In this study, 51-92\% admissions of early onset cases especially of neonatal age presented with nonspecific symptoms like lethargy (odd ratio 1.69-Table 4), fever, poor feeding, vomiting, dehydration, muscular hypotonia, respiratory symptoms, severe acidosis, metabolic crisis, and thrombocytopenia. These were significant findings $(P$ value $<0.05-$ Table 3). Coma and convulsions were the presenting features in $13-18 \%$ of admissions. This clinical presentation is in line with other case series $[2,7,9]$.

Feeding problems often combined with heavy vomiting were found the most common (51-77\%) initial symptoms. However, other researchers reported these symptoms slightly more frequent as $83 \%-91 \%[2,7]$. The cause may be improvement in management measures and nutrition of PA. Clinical acute or chronic neurological manifestations are caused by accumulation of toxic metabolites $[2,7]$. Our $13-68 \%$ admissions had CNS symptoms like apathy/lethargy, coma, and seizures. Other reports are also almost similar [2, 7]. Convulsions were reported in $43 \%$ of patients [2]. However, the observations in the current study were much lower as $13 \%$ only. Similarly, respiratory symptoms like cough, dyspnoea, and apnoea were frequently observed as $36 \%$ in our patients, while these figures were reported as $57 \%$ in the Austrian study [2]. The difference in frequency of these findings is probably due to prolonged period of the Austrian study (15 years), because complications increase with advancing age of patients with PA. Less common clinical features observed in the present study were acidotic breathing, weight loss, loose motion, and constipation, in keeping with other reports [2, 12].

Regarding physical findings (Table 2), dehydration was found in $92 \%$ admissions, which is consistent with other 
TABLE 3: Important clinical features and laboratory parameters on initial presentations in $n=133$ admissions of 26 patients with PA.

\begin{tabular}{|c|c|c|c|}
\hline Findings/investigations & $n(\%) /$ mean $(\mathrm{SD})$ & CI, 95\% & $P$ value \\
\hline \multicolumn{4}{|l|}{ Symptoms } \\
\hline Lethargy & $91(68.4)$ & $85.07-96.93$ & $<0.001$ \\
\hline Fever & $81(60.9)$ & $75.72-86.28$ & $<0.001$ \\
\hline Poor feeding & $68(51.1)$ & $63.57-72.43$ & $<0.001$ \\
\hline Vomiting & $102(76.7)$ & $95.35-108.65$ & $<0.001$ \\
\hline Dyspnoea/cough/others $^{\dagger}$ & $48(36.1)$ & $44.87-51.13$ & $<0.001$ \\
\hline Loss of consciousness & $24(18)$ & $22.44-25.56$ & 0.002 \\
\hline Seizures & $17(12.8)$ & $15.89-18.11$ & 0.028 \\
\hline \multicolumn{4}{|l|}{ Physical findings/diagnosis } \\
\hline Dehydration & $123(92.4)$ & $114.99-131.01$ & $<0.001$ \\
\hline Hypotonia & $81(61.9)$ & $75.63-86.37$ & $<0.001$ \\
\hline Encephalopathy & $6(4.5)$ & $5.61-6.39$ & 0.437 \\
\hline Metabolic crisis & $111(83.4)$ & $103.77-118.23$ & $<0.001$ \\
\hline Respiratory diseases ${ }^{\ddagger}$ & $40(30.1)$ & $37.39-42.61$ & $<0.001$ \\
\hline Coma & $6(4.5)$ & $5.61-6.39$ & 0.437 \\
\hline Sepsis (culture positive) & $8(6)$ & $7.48-8.52$ & 0.300 \\
\hline \multicolumn{4}{|l|}{ Laboratory parameters } \\
\hline S. ammonia (umol/L) & $308.3[279.1]$ & $284.10-332.50$ & $<0.001$ \\
\hline S. glucose $(\mathrm{mg} / \mathrm{dL})$ & $91.1[67.5]$ & $90.54-91.66$ & 0.262 \\
\hline S. total protein $(\mathrm{g} / \mathrm{dL})$ & $5.75[1]$ & $5.61-5.77$ & 0.863 \\
\hline S. albumen $(\mathrm{g} / \mathrm{dL})$ & $2.97[0.7]$ & $2.91-3.03$ & 0.904 \\
\hline S. calcium total (mg/dL) & $8.04[1]$ & $7.95-8.13$ & 0.863 \\
\hline Haemoglobin $(\mathrm{g} / \mathrm{dL})$ & $10.96[2.2]$ & $10.77-11.15$ & 0.703 \\
\hline RBCs count $\left(\times 10^{6} / \mathrm{mm}^{3}\right.$ & $4.23[0.9]$ & $4.15-4.31$ & 0.876 \\
\hline Platelets count $\left(\times 10^{3} / \mathrm{mm}^{3}\right)$ & $206[144]$ & $193.51-218.49$ & $<0.001$ \\
\hline $\operatorname{TLC}\left(\times 10^{3} / \mathrm{mm}^{3}\right)$ & $5.34[3.1]$ & $5.07-5.61$ & 0.592 \\
\hline $\mathrm{pH}$ & $7.24[0.21]$ & $7.22-7.26$ & 0.972 \\
\hline Base excess $(\mathrm{mmol} / \mathrm{L})$ & $-14.6[6.9]$ & $14.00-15.20$ & 0.234 \\
\hline $\mathrm{HCO}_{3}(\mathrm{mmol} / \mathrm{L})$ & $13.2[5.95]$ & $12.68-13.72$ & 0.304 \\
\hline
\end{tabular}

${ }^{\dagger}$ Acidotic breathing aspiration, apnoea, suppurative otitis media, sore throat, flu; ${ }^{\ddagger}$ pneumonia, chronic lung disease, upper respiratory tract infection, and hyper reactive airway disease; RBCs: red blood cells, TLC: total leukocyte count, ANC: absolute neutrophil count, $\mathrm{HCO}_{3}$ : bicarbonate.

TABLE 4: Gender-wise odd ratio analyses for clinical and laboratory findings.

\begin{tabular}{|c|c|c|c|}
\hline Lethargy/apathy/somnolence & Male & Female & Total \\
\hline Yes & 12 & 5 & 17 \\
\hline No & 4 & 5 & 9 \\
\hline \multicolumn{4}{|c|}{ Odds ratio 1.69 , chi square $0.234, P$ value 2.485} \\
\hline \multicolumn{4}{|l|}{ Respiratory diseases } \\
\hline Yes & 7 & 6 & 13 \\
\hline No & 9 & 4 & 13 \\
\hline \multicolumn{4}{|c|}{ Odds ratio 1.99 , chi square $0.65, P$ value 0.428} \\
\hline \multicolumn{4}{|l|}{ Hypocalcaemia $(<8.4$ mg/dL) } \\
\hline Yes & 9 & 7 & 16 \\
\hline No & 7 & 3 & 10 \\
\hline \multicolumn{4}{|c|}{ Odds ratio 1.815 , chi square $0.589, P$ value 0.585} \\
\hline \multicolumn{4}{|c|}{ Anaemia (haemoglobin < $10 \mathrm{~g} / \mathrm{dL}$ ) } \\
\hline In the range & 5 & 2 & 7 \\
\hline Outside the range & 11 & 8 & 19 \\
\hline \multicolumn{4}{|c|}{ Odds ratio 0.55 , chi square $0.529, P$ value 0.658} \\
\hline
\end{tabular}


reports [2]. In this study, children showed tendency to failure to thrive that is reflected by their mean weight for age, $71.2 \%$ (normal >90\%) [10], and mean height/length for age, $91 \%$ (normal $>95 \%$ ), Contrarily, some other studies showed more impact of the disease on height, as compared to weight of the patients $[2,13]$. This is probably because of advancement in nutrition and management of PA with time, because height is affected considerably in more frequent and prolonged period of decompensations. As shown by Schreiber et al. [1], our patients also revealed some neurological manifestations like encephalopathy, disturbances in tone, and deep tendon reflexes in $5-50 \%$ admissions.

Regarding diagnoses of the diseases with which PA patients were admitted, metabolic crises were encountered in $83 \%$, respiratory problems in $30 \%$ (odd ratio $1.99-$ Table 4 ), and diarrhoea in $9 \%$ admissions (Table 2). Although clinical sepsis was suspected in $1 / 3$, admissions, it was proved by blood culture, in $6 \%$ cases only, in contrast to three times higher report as $18 \%$ [7]. This difference may be due to variable quality of laboratory facilities.

4.2. Laboratory Considerations. For diagnosis of propionic acidaemia, in this study, tandem mass spectrometry results showed mean propionylcarnitine (C3) $18.76 \mathrm{umol} / \mathrm{L}$ (normal: $<4.33$ ) and mean $\mathrm{C} 3 / \mathrm{C} 2$ ratio 1.86 (normal: <0.1). However, Huang and coworkers [14] noted these figures to be a bit lower (12.41 umol/L, and $1.31 \mathrm{umol} / \mathrm{L}$ resp.), while another report of C3 level is on a higher side, as $22.13 \mathrm{umol} / \mathrm{L}$ [12].

In PA, worsening metabolic acidosis has been described in stressful conditions like fever, infection, vomiting, and physical and psychological trauma [9]. In the present study, three-quarter of admissions were found to be associated with metabolic acidosis which is broadly comparable with another report as $90 \%$ [2].

In the current study, hyperammonaemia ( $>80 \mathrm{umol} / \mathrm{L}$ ) was observed in $96 \%$ admissions with mean ammonia level as $308 \mathrm{umol} / \mathrm{L}$ and $4.5 \%$ admissions showed level $>1000 \mathrm{umol} / \mathrm{L}$. Our $6 \%$ children, who had hyperammonaemia, underwent peritoneal dialysis for quick recovery. Walter and coresearchers [7] found hyperammonaemia in $100 \%$ cases of PA with mean ammonia level as $350 \mathrm{umol} / \mathrm{L}$. Their $18 \%$ patients had ammonia level $>1000 \mathrm{umol} / \mathrm{L}$ who all (100\%) underwent peritoneal dialysis. These findings are almost in line with those of the present study. Hypocalcaemia $(<8.4 \mathrm{mg} / \mathrm{dL})$ was encountered in $2 / 3$ of admissions (odd ratio $1.82-$ Table 4 ) which is comparable with another report [7]. In line with Alberola et al. [5], the current work revealed hypoglycaemia in $12 \%$ and hyperglycaemia in $2 \%$ admissions. We observed hypocalcaemia $(<5.5 \mathrm{~g} / \mathrm{dL})$ in $1 / 4$ (one quarter) of admissions as compared to those of the $1 / 3$ [2]. Hypoalbuminemia $(<3.5 \mathrm{~g} / \mathrm{dL})$ was also noted in three-quarter of admissions in this study. As reported by Delgado and co-researchers [12], the present study also revealed mildly disturbed liver enzymes in $16-40 \%$ of admissions. These findings are probably due to impact of metabolic derangements on liver efficiency. Similar to Lehnert and co-workers [2], we noted ketonurea in $1 / 3$ of admissions.

During metabolic crises, propionate inhibits the growth of bone marrow stem cells, leading to leukocytopenia, thrombocytopenia, and/or pancytopenia-a condition which has been described frequently in PA [2]. Neutropenia was reported in $27 \%$ and thrombocytopenia in $18 \%$ patients [11] as compared to our findings as $36 \%$ and $39 \%$, respectively. Anaemia (Hb. $<10 \mathrm{~g} / \mathrm{dL}$ ) was found in $26 \%$ admissions (odd ratio 0.55 - Table 4 ) as compared to $72 \%$ in another report [2]. This difference is probably due to hilly area inhabitants of this study, where comparatively hypoxic environment stimulates erythropoiesis leading to high haemoglobin and also due to advancement in nutrition for PA. Consistently with other reports, radiological studies revealed metabolic bone disease in some of our patients $[2,5]$. Similarly, computerized tomography and MRI brain showed generalised brain oedema in $17 \%$, cerebral atrophy in $25 \%$, and multiple cerebral infarcts plus haemorrhage in $2 \%$ admissions. These results are consistent with another study [9].

There were some limitations in this study, firstly due to unavailability of complete records of some of the patients, and secondly, this was a retrospective study with little number of patients. Further multicentre, longitudinal studies are needed to better elucidate the clinical spectrum of the disease.

\section{Conclusion}

We have a large gap in knowledge about the path from biochemical abnormality to clinical symptoms and signs of PA. We need to focus our efforts on improving our understanding of PA. This report may be helpful in extending the knowledge about clinical features and disturbances of laboratory parameters in patients with PA. Aggressive identification and initiation of therapy are necessary to prevent severe morbidity and mortality in patients with PA whose life quality is profoundly affected. So, more extensive, centralized newborn screening program is thus imperative.

\section{Abbreviations}

PA: Propionic acidaemia

KSA: Kingdom of Saudi Arabia

H/O: History of

NICU: Neonatal intensive care unit

NG: Nasogastric (tube)

ANC: Absolute neutrophil count

C3: Propionylcarnitine

MRI: Magnetic resonance imaging

CNS: Central nervous system.

\section{Conflict of Interests}

The author declares that he has no conflict of interests.

\section{Acknowledgment}

This study was conducted in Central Aseer Hospital Abha, Kingdom of Saudi Arabia.

\section{References}

[1] J. Schreiber, K. A. Chapman, M. L. Summar et al., "Neurological considerations in propionic acidemia," Molecular Genetics and Metabolism, vol. 105, no. 1, pp. 10-15, 2012. 
[2] W. Lehnert, W. Sperl, T. Suormala, and E. R. Baumgartner, "Propionic acidaemia: clinical, biochemical and therapeutic aspects. Experience in 30 patients," European Journal of Pediatrics, vol. 153, supplement 1, pp. S68-S80, 1994.

[3] N. Kaya, M. Al-Owain, A. Al-Bakheet et al., "Array comparative genomic hybridization (aCGH) reveals the largest novel deletion in PCCA found in a Saudi family with propionic acidemia," European Journal of Medical Genetics, vol. 51, no. 6, pp. 558-565, 2008.

[4] V. R. Sutton, K. A. Chapman, A. L. Gropman et al., "Chronic management and health supervision of individuals with propionic acidemia," Molecular Genetics and Metabolism, vol. 105, no. 1, pp. 26-33, 2012.

[5] T. M. Alberola, R. Bautista-Llácer, X. Vendrell et al., "Case report: birth of healthy twins after preimplantation genetic diagnosis of propionic acidemia," Journal of Assisted Reproduction and Genetics, vol. 28, no. 3, pp. 211-216, 2011.

[6] L. Pena, J. Franks, K. A. Chapman et al., "Natural history of propionic acidemia," Molecular Genetics and Metabolism, vol. 105, no. 1, pp. 5-9, 2012.

[7] J. H. Walter, J. E. Wraith, and M. A. Cleary, "Absence of acidosis in the initial presentation of propionic acidaemia," Archives of Disease in Childhood, vol. 72, no. 3, pp. F197-F199, 1995.

[8] P. T. Ozand, M. Rashed, G. G. Gascon et al., "Unusual presentations of propionic acidemia," Brain and Development, vol. 16, pp. 46-57, 1994.

[9] K. A. Chapman, A. Gropman, E. MacLeod et al., "Acute management of propionic acidemia," Molecular Genetics and Metabolism, vol. 105, no. 1, pp. 16-25, 2012.

[10] V. Keane, Assessment of Growth, edited by R. M. Kleigman, R. E. Behrman, H. B. Jenson, B. F. Stanton, WB Saunders, Philadelphia, Pa, USA, 18th edition, 2007.

[11] H. Moammar, G. Cheriyan, R. Mathew, and N. Al-Sannaa, "Incidence and patterns of inborn errors of metabolism in the Eastern Province of Saudi Arabia, 1983-2008," Annals of Saudi Medicine, vol. 30, no. 4, pp. 271-277, 2010.

[12] C. Delgado, C. Macías, M. de la Sierra García-Valdecasas, M. Pérez, L. R. del Portal, and L. M. Jiménez, "Sub acute presentation of propionic acidemia," Journal of Child Neurology, vol. 22, no. 12, pp. 1405-1407, 2007.

[13] S. B. van der Meer, F. Poggi, M. Spada et al., "Clinical outcome and long term management of 17 patients with propionic acidaemia," European Journal of Pediatrics, vol. 155, no. 3, pp. 205210, 1996.

[14] X. Huang, L. Yang, F. Tong, R. Yang, and Z. Zhao, "Screening for inborn errors of metabolism in high-risk children: a 3-year pilot study in Zhejiang Province, China," BMC Pediatrics, vol. 12, article 18, 2012. 


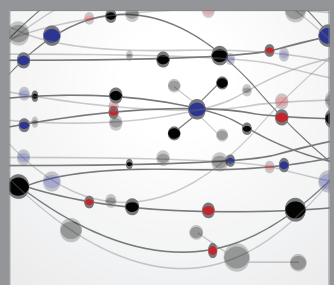

The Scientific World Journal
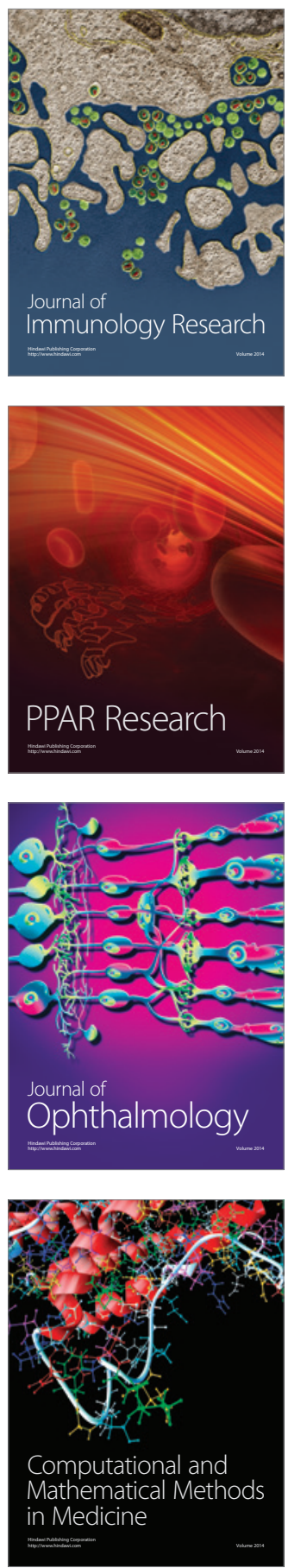

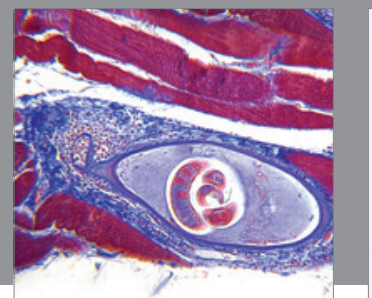

Gastroenterology

Research and Practice
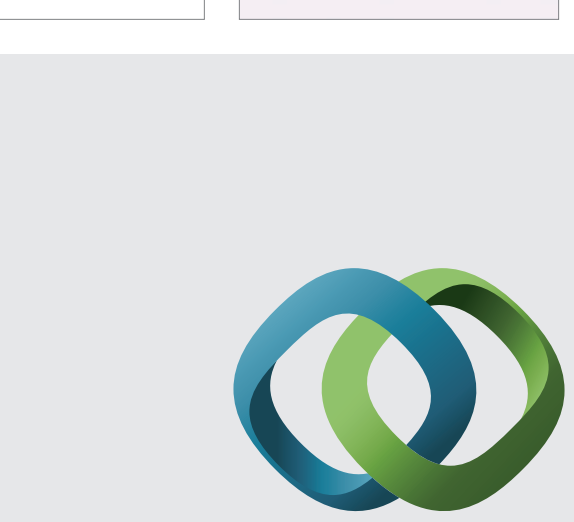

\section{Hindawi}

Submit your manuscripts at

http://www.hindawi.com
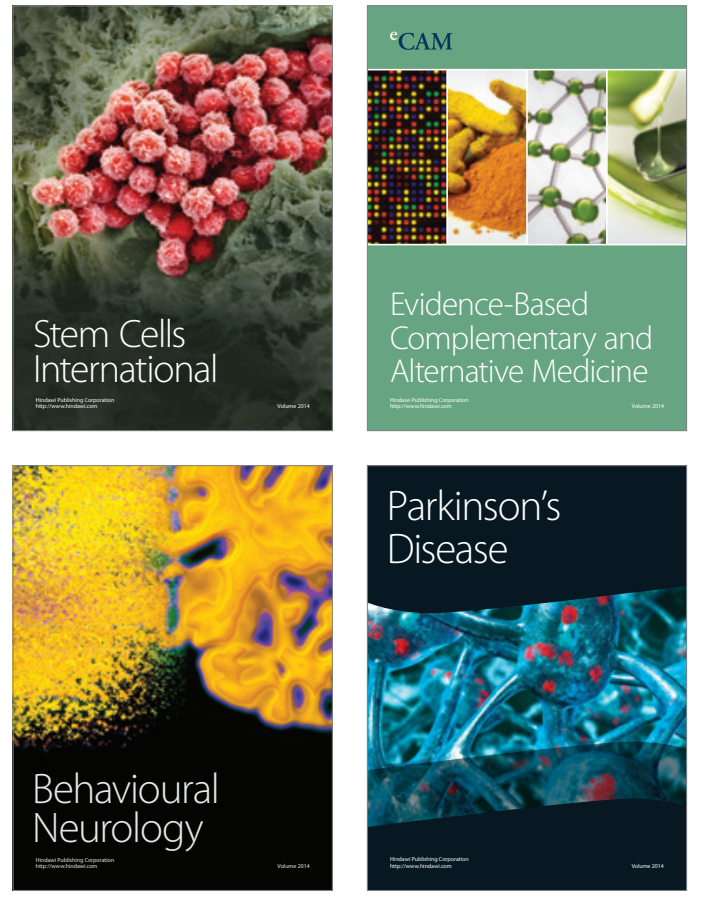
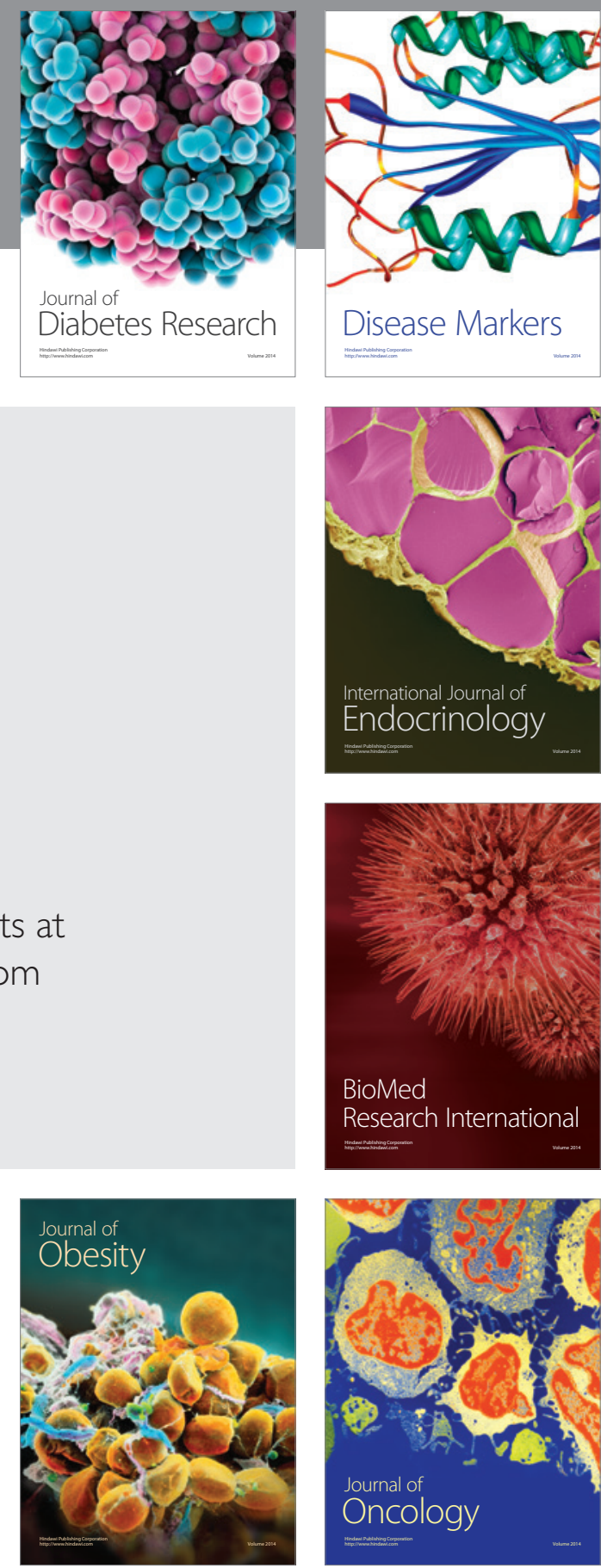

Disease Markers
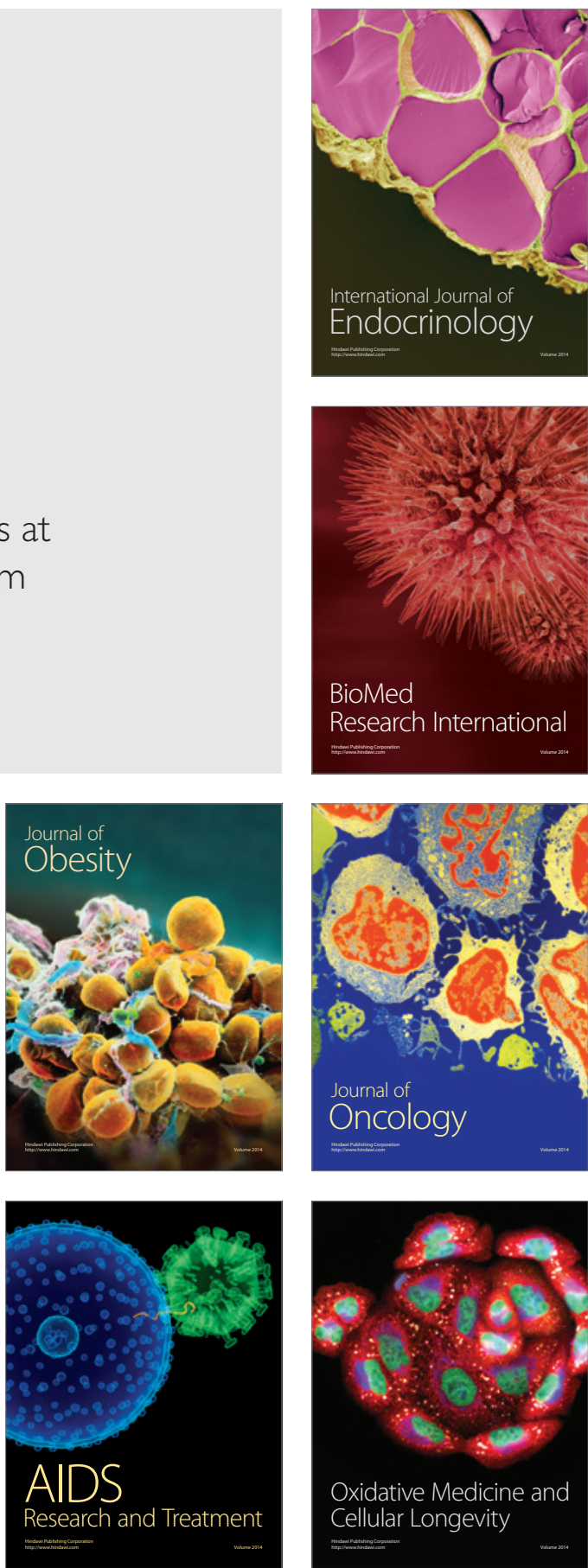